\title{
Study on the transcriptome for breast muscle of chickens and the function of key gene $R A C 2$ on fibroblasts proliferation
}

Genxi Zhang ${ }^{1,2}$, Pengfei Wu $u^{1,2^{*}} \mathbb{D}$, Kaizhi Zhou ${ }^{1,2}$, Mingliang He ${ }^{1,2}$, Xinchao Zhang ${ }^{1,2}$, Cong Qiu ${ }^{3}$, Tingting Li, ${ }^{1,2}$, Tao Zhang ${ }^{1,2}$, Kaizhou Xie ${ }^{1,2}$, Guojun Dai ${ }^{1,2}$ and Jinyu Wang ${ }^{1,2}$

\begin{abstract}
Background: Growth performance is significant in broiler production. In the growth process of broilers, gene expression varies at different growth stages. However, limited research has been conducted on the molecular mechanisms of muscle growth and development in yellow-feathered male chickens.

Results: In the study, we used RNA-seq to study the transcriptome of the breast muscle of male Jinghai yellow chickens at 4 (M4F), 8 (M8F) and 12 weeks (M12F) of age. The results showed that 4608 differentially expressed genes (DEGs) were obtained by comparison in pairs of the three groups with Fold Change (FC) $\geq 2$ and False Discovery Rate $(F D R) \leq 0.05$, and 83, 3445 and 3903 DEGs were obtained separately from M4FvsM8F, M4FvsM12F and M8FvsM12F. Six genes were found as co-differentially expressed in the three age groups, namely SNCG, MYH1A, ARHGDIB, ENSGALG00000031598, ENSGALG00000035660 and ENSGALG00000030559. The GO analysis showed that 0, 304 and 408 biological process (BP) were significantly enriched in M4FvsM8F, M4FvsM12F and M8FvsM12F groups, respectively. KEGG pathway enrichment showed that 1, 2, 4 and 4 pathways were significantly enriched in M4FvsM8F, M4FvsM12F, M8FvsM12F and all DEGs, respectively. They were steroid biosynthesis, carbon metabolism, focal adhesion, cytokine-cytokine receptor interaction, biosynthesis of amino acids and salmonella infection. We constructed short hairpin RNA (shRNA) to interfere the differentially expressed gene RAC2 in DF-1 cells and detected mRNA and protein expression of the downstream genes PAK1 and MAPK8. Results of qPCR showed that RAC2, PAK1 and MAPK8 mRNA expression significantly decreased in the shRAC2-2 group compared with the negative control (NC) group. Western Blot (WB) results showed that the proteins of RAC2, PAK1 and MAPK8 also decreased in the shRAC2-2 group. Cell Counting Kit-8 (CCK-8) and 5-Ethynyl-2'-deoxyuridine (EdU) assay both showed that the proliferation of DF-1 cells was significantly inhibited after transfection of shRAC2-2.

Conclusions: The results of RNA-seq revealed genes, BP terms and KEGG pathways related to growth and development of male Jinghai yellow chickens, and they would have important guiding significance to our production practice. Further research suggested that RAC2 might regulate cell proliferation by regulating PAKS/ MAPK8 pathway and affect growth of chickens.
\end{abstract}

Keywords: Jinghai yellow chicken, Growth and development, RNA-seq, qPCR, RNAi

\footnotetext{
* Correspondence: wu_p fei@163.com

${ }^{1}$ College of Animal Science and Technology, Yangzhou University, Yangzhou 225009, China

${ }^{2}$ Joint International Research Laboratory of Agriculture \& Agri-Product Safety, Yangzhou University, Yangzhou 225009, China

Full list of author information is available at the end of the article
}

(c) The Author(s). 2021 Open Access This article is licensed under a Creative Commons Attribution 4.0 International License, which permits use, sharing, adaptation, distribution and reproduction in any medium or format, as long as you give appropriate credit to the original author(s) and the source, provide a link to the Creative Commons licence, and indicate if changes were made. The images or other third party material in this article are included in the article's Creative Commons licence, unless indicated otherwise in a credit line to the material. If material is not included in the article's Creative Commons licence and your intended use is not permitted by statutory regulation or exceeds the permitted use, you will need to obtain permission directly from the copyright holder. To view a copy of this licence, visit http://creativecommons.org/licenses/by/4.0/. The Creative Commons Public Domain Dedication waiver (http://creativecommons.org/publicdomain/zero/1.0/) applies to the data made available in this article, unless otherwise stated in a credit line to the data. 


\section{Background}

Chicken meat has the nutritional characteristics of high protein, low fat and low calorie. Yellow-feathered broilers, as germplasm resources of local breeds in China, are more and more popular with consumers because of their strong disease resistance and delicious meat [1-5]. However, the growth rate of indigenous chicken is slower than that of commercial large whitefeathered broilers $[5,6]$. In order to improve their growth performance, it is necessary to study the growth and development mechanism regulation. In the breeding of broilers, the ratio of male to female chicken in natural mating is generally $1: 8-12$, but the ratio in artificial insemination can reach 1:20-30, even up to 1:50. Half of the offspring's genome comes from the roosters, so their performance has a greater impact on the population growth performance than that of hens. However, limited research has been conducted on the molecular mechanisms of muscle growth and development in yellowfeathered male chickens.

With the advent of post-genomic era, genomics technologies such as transcriptome, proteome, metabonome have emerged, among which RNA-seq was widely used in the field of livestock and poultry [7-9]. It has become the preferred technology for researchers to solve various complex biological problems in recent years. Xu et al. [7] studied the Longissimus dorsi muscle of two pig breeds by RNA-seq. The results showed that ACSL1, $F A B P 3, U C P 3$ and PDK4 could be used as candidate genes related to lipid metabolism, and $A S B 2, M S T N$, ANKRD 1 and ANKRD2 could be used as candidate genes for skeletal muscle growth and development. Zhang et al. [8] studied uterine tissue of 49-week-old Luodao white chickens with low-quality eggshell and normal-quality eggshell and a total of 889 DEGs were detected. Pathway analysis showed that these genes were mainly related to calcium transport and calcium signaling pathway. Ren et al. [9] collected 6-week-old pectoral muscle of slow-growing (Gushi, GS) and fast-growing (Arbor Acres, AA) chicken breeds for RNA-seq. They screened 4815 differentially expressed lncRNAs, identifying two muscle-specific IncRNAs (TCONS_00064133 and TCONS_00069348).

RAC family small GTPase 2 (RAC2) is a member of the small $G$ protein family. The small $G$ protein is a kind of low molecular weight protein, which can catalyze the transformation between GTP and GDP. It is mainly distributed in the cytoplasm or plasma membrane, and can regulate various cellular physiological processes [10]. The small G protein family associated with rat sarcoma (Ras) contains about 150 proteins, which can be divided into six families: Rho, Rab, Ras, Ran, Arf and Rad [11]. Among them, Rho protein plays an important role in regulating the structure of the cytoskeleton network and the expression of related genes, ultimately regulating many cellular behaviors [12]. The members of $R A C$ protein ( $R A C 1, R A C 2, R A C 3$ ) belong to Rho family. $R A C$ protein family members regulate cellular behavior in many ways and the most important and well-studied pathway is to activate p21-activated kinases $(P A K s)$. At present, there are some studies on the mechanism of RAC1 regulating cells through $P A K S / M A P K S$ signaling pathway [13-15]. However, the function of $R A C 2$ regulating chicken growth and development through the PAKS/MAPKS has not been reported.

In our study, an RNA-seq analysis of the breast muscle of male Jinghai yellow chickens at different growth stages was carried out. We selected a key DEG RAC2 from RNA-seq and explored its function on fibroblasts proliferation. The research will help us lay a theoretical foundation for further understanding the regulation mechanism of muscle growth and development during chicken growth.

\section{Results}

RNA quality control and mapping

The results of $1 \%$ agarose gel electrophoresis for the total RNA were shown in Figure S1. Two clear bands, $28 \mathrm{~S}$ and $18 \mathrm{~S}$, in each sample were displayed, which suggested that the total RNA did not degrade. The detection results of purity, concentration and integrity for total RNA were shown in Table S3. It showed that the concentration of each sample is within the normal range, with high purity and high integrity. In conclusion, the RNA samples could be used for cDNA library construction.

The data quality control results (Table S4) showed that the clean bases of each sample reached above 7.56G (M8F_1). The percentage of the clean base with 99.9\% correct recognition rate (Q30) was more than 90.43\% (M4F_2) and the GC content in each sample ranged from 53.93 to $55.16 \%$, indicating that there was no base separation. The sequencing data was good and can be used for a series of subsequent data analysis.

In each sample, the proportion of clean reads mapped to the reference genome was more than $73.63 \%$ (M4F_ 3 ), which has reached the standard of $70 \%$, and other indicators were also within the normal range (Table S5). Figure S2 showed the distribution of clean reads mapped to the reference genome located in exon, intron and intergenic region. The number of clean reads mapped to exon accounted for the highest proportion in each sample, which was consistent with the reality.

\section{Screening and functional enrichment analysis of DEGs}

A total of 4608 DEGs were obtained with the standard $\mathrm{FC} \geq 2$ and $\mathrm{FDR} \leq 0.05$ from comparison in pairs of M4F, M8F and M12F. The results showed that 83, 3445 and 
3903 DEGs were separately obtained from M4FvsM8F, M4FvsM12F and M8FvsM12F (Fig. 1a). There were 37 up-regulated genes and 46 down-regulated genes in M8F compared with M4F, 1936 up-regulated genes and 1509 down-regulated genes in M12F compared with M4F, and 2308 up-regulated genes and 1595 downregulated genes in M12F compared M8F. Further analysis showed that six common DEGs were found (Table 1, Fig. 1b), but only three of them were annotated, namely SNCG, MYH1A and ARHGDIB, suggesting that the three genes may be closely related to growth and development at early stages of the Jinghai yellow chicken.

The FPKM of 4608 DEGs was used for hierarchical clustering analysis. The distance between samples was calculated using the expression of DEGs in each sample. The result (Fig. 1c) showed that each sample in the same group was gathered together, which further explained the reliability of the sample selection. The gene expression patterns of breast muscle for chickens were more similar at 4 weeks and 8 weeks. However, it changed greatly at 12 weeks.

GO analysis was carried out for 83, 3445 and 3903 DEGs obtained from M4FvsM8F, M4FvsM12F and M8FvsM12F, respectively. Focusing on the biological processes (BP), 304 and 408 terms (corrected p-value < 0.05) were found for M4FvsM12F and M8FvsM12F groups, and no significant BP terms were found for the M4FvsM8F group. Figure 2 showed the histograms for the top 30 terms in the three comparison groups,
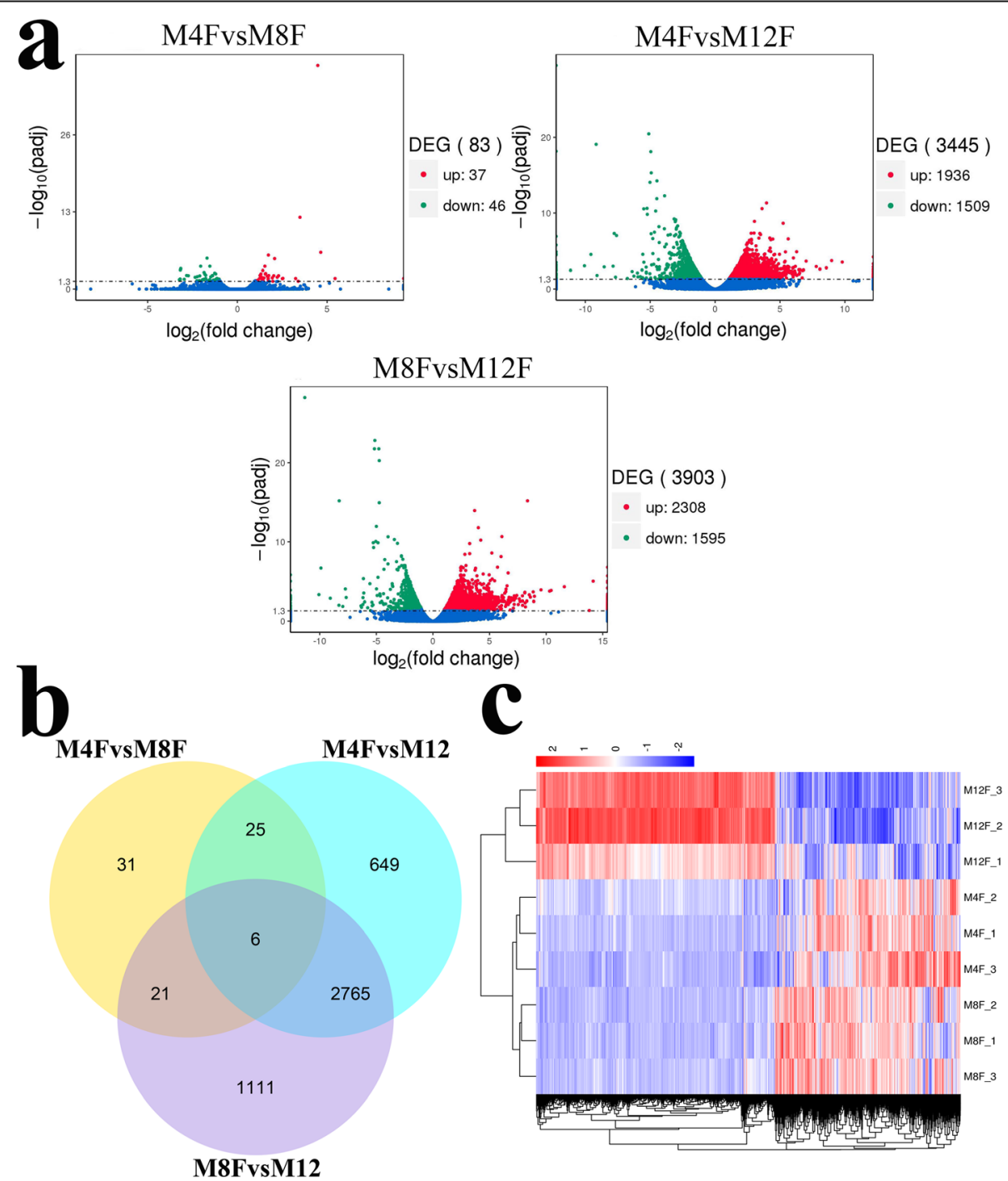

Fig. 1 Analysis of differentially expressed genes. a The volcano plot of differentially expressed genes. $\mathbf{b}$ The venn plot of differentially expressed genes. c The hierarchical clustering of differentially expressed genes. M4F: Breast muscle of male chickens at 4 weeks; M8F: Breast muscle of male chickens at 8 weeks; M12F: Breast muscle of male chickens at 12 weeks 
Table 1 Co-differentially expressed genes

\begin{tabular}{lll}
\hline Ensemble ID & Gene name & Full name of genes \\
\hline ENSGALG00000002015 & SNCG & synuclein gamma \\
ENSGALG00000037864 & MYHIA & myosin, heavy chain 1A, skeletal muscle \\
ENSGALG00000011738 & ARHGDIB & Rho GDP dissociation inhibitor beta \\
ENSGALG00000031598 & - & - \\
ENSGALG00000035660 & - & - \\
ENSGALG00000030559 & - & - \\
\hline
\end{tabular}

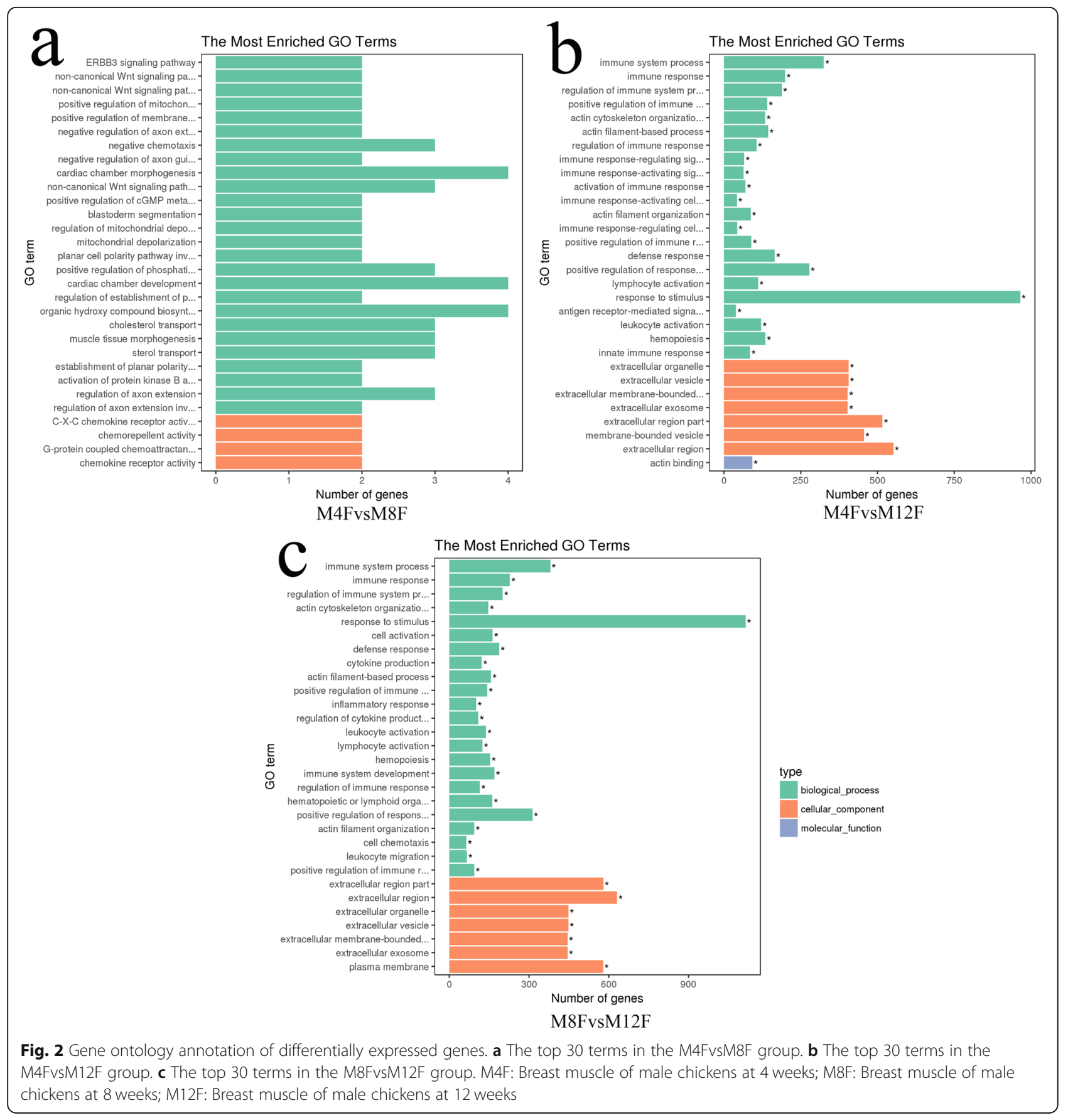


respectively. The results revealed that no significant enrichment term was found in the M4FvsM8F group (Fig. 2a), which may be due to the small number of DEGs. In the two comparison groups M4FvsM12F and M8FvsM12F, several significantly enriched BP terms (Fig. 2b and c) were obtained and some of them were related to growth and development of chicken (Table 2), including muscle structure development, actin cytoskeleton organization, cell proliferation, cell proliferation, cellular developmental process and cytokine production, etc.

KEGG pathway analysis was performed for the DEGs. The results (Fig. 3, Table 3) showed that 1, 2, 4 and 4 pathways were significantly enriched (corrected $p$-value $\leq 0.05$ ) in groups M4FvsM8F (Fig. 3a), M4FvsM12F (Fig. 3b), M8FvsM12F (Fig. 3c) and all the DEGs (Fig. 3d), respectively. They are steroid biosynthesis, carbon metabolism, focal adhesion, cytokine-cytokine receptor interaction, biosynthesis of amino acids and salmonella infection. The first five pathways were all closely related to chicken growth and development, and had important reference value in scientific research and production.

\section{Validation of RNA-seq results using $\mathrm{qPCR}$}

Nine genes were selected for qPCR to verify the accuracy of RNA-seq (Fig. 4). Pearson correlation coefficient (r)

Table 2 The biological process related to growth and development

\begin{tabular}{|c|c|c|c|c|c|}
\hline Group & $\begin{array}{l}\text { GO } \\
\text { accession }\end{array}$ & Description & $\begin{array}{l}\text { Correctedp- } \\
\text { value }\end{array}$ & $\begin{array}{l}\text { DEGs } \\
\text { number }\end{array}$ & Growth related genes \\
\hline \multirow[t]{9}{*}{ M4FvsM12F } & $\begin{array}{l}\text { GO: } \\
0030036\end{array}$ & actin cytoskeleton organization & $4.66 \mathrm{E}-10$ & 134 & ACTA1; FGF7; MYL1; TGFB1; MYH9; MEF2A \\
\hline & $\begin{array}{l}\text { GO: } \\
0001816\end{array}$ & cytokine production & 7.94E-07 & 102 & TGFB1; MAPK11; IRF4; PRKCD; IRF8 \\
\hline & $\begin{array}{l}\text { GO: } \\
0051493\end{array}$ & $\begin{array}{l}\text { regulation of cytoskeleton } \\
\text { organization }\end{array}$ & $3.02 \mathrm{E}-06$ & 91 & FGF13; TGFB1; MYL1; PAK3; KIF18A; ACTN2 \\
\hline & $\begin{array}{l}\text { GO: } \\
0007010\end{array}$ & cytoskeleton organization & $1.26 \mathrm{E}-05$ & 215 & FGF13; FGF7; TGFB1; ACTA1; MYH9; MYL1 \\
\hline & $\begin{array}{l}\text { GO: } \\
0008283\end{array}$ & cell proliferation & 0.000199 & 249 & MYDGF; ING5; FGF7; TGFB1; IGF2; NGFR; IGFBP4; IGF2BP1 \\
\hline & $\begin{array}{l}\text { GO: } \\
0007165\end{array}$ & signal transduction & 0.000229 & 643 & $\begin{array}{l}\text { WNT5B; MEF2C; MEF2A; GDF8; GDF3; GFI1; MYDGF; ING5; } \\
\text { FGF13; IGFBP4 }\end{array}$ \\
\hline & $\begin{array}{l}\text { GO: } \\
0003012\end{array}$ & muscle system process & 0.00951 & 59 & MYL1; MYLK2; FGF13; TNNT3; TNNC2; MEF2C; MSTN \\
\hline & $\begin{array}{l}\text { GO: } \\
0048869\end{array}$ & cellular developmental process & 0.023947 & 477 & $\begin{array}{l}\text { GDF3; GAS1; TGFB1; IGF2BP1; GFI1; ACTA1; MYH9; WNT9A; } \\
\text { WNT5B }\end{array}$ \\
\hline & $\begin{array}{l}\text { GO: } \\
0061061\end{array}$ & muscle structure development & 0.034591 & 89 & TGFB1; MYH9; ACTA1; BTG1; MEF2C; MEF2A; MEF2D; MSTN \\
\hline \multirow[t]{10}{*}{ M8FvsM12F } & $\begin{array}{l}\text { GO: } \\
0001816\end{array}$ & cytokine production & 2.39E-09 & 122 & TGFB3; TGFBR2; TGFB1; WNT5A; TGFB3 \\
\hline & $\begin{array}{l}\text { GO: } \\
0030036\end{array}$ & actin cytoskeleton organization & $1.22 \mathrm{E}-09$ & 147 & MYH9; ACTN1; ARHGAP35; MEF2A; TGFB1; FGF7 \\
\hline & $\begin{array}{l}\text { GO: } \\
0008283\end{array}$ & cell proliferation & $6.81 \mathrm{E}-06$ & 290 & $\begin{array}{l}\text { MSTN; MEF2C; TGFB1; TGFBR2; WNT2; WNT5A; WNT9A; } \\
\text { IGF2; IGFBP4; IGF2BP1 }\end{array}$ \\
\hline & $\begin{array}{l}\text { GO: } \\
0032956\end{array}$ & $\begin{array}{l}\text { regulation of actin cytoskeleton } \\
\text { organization }\end{array}$ & $1.35 \mathrm{E}-05$ & 72 & TGFB3; TGFB1; TGFBR2; ACTN2; MEF2C; MYL1; \\
\hline & $\begin{array}{l}\text { GO: } \\
0048731\end{array}$ & system development & 0.008234 & 588 & $\begin{array}{l}\text { MSTN; IGF2BP1; MEF2A; MEF2C; MEF2D; WNT5A; WNT2; } \\
\text { WNT9A; MYH9 }\end{array}$ \\
\hline & $\begin{array}{l}\text { GO: } \\
0048513\end{array}$ & organ development & 0.004239 & 445 & $\begin{array}{l}\text { MSTN; WNT2; WNT9A; WNT16; IGF2BP1; MEF2A; MEF2C; } \\
\text { MYH9 }\end{array}$ \\
\hline & $\begin{array}{l}\text { GO: } \\
0051094\end{array}$ & $\begin{array}{l}\text { positive regulation of } \\
\text { developmental process }\end{array}$ & 0.02081 & 189 & WNT9A; TGFBR2; TGFB1; TGFB3; WNT5A; IGF2BP1; MEF2C; \\
\hline & $\begin{array}{l}\text { GO: } \\
0032502\end{array}$ & developmental process & 0.026142 & 756 & $\begin{array}{l}\text { MSTN; GDF3; MEF2A; MEF2C; MEF2D; MYH9; MYL2K; TGFB1; } \\
\text { TGFB3; TGFBR3 }\end{array}$ \\
\hline & $\begin{array}{l}\text { GO: } \\
0061061\end{array}$ & muscle structure development & 0.041363 & 99 & $\begin{array}{l}\text { WNT2; TGFB1; MEF2A; WNT5A; MEF2D; MSTN; MYH9; } \\
\text { ACTN1 }\end{array}$ \\
\hline & $\begin{array}{l}\text { GO: } \\
0048869\end{array}$ & cellular developmental process & 0.042022 & 539 & MSTN; GDF3; IGF2BP1; TGFB1; TGFB3; TGFBR2; MYH9 \\
\hline
\end{tabular}




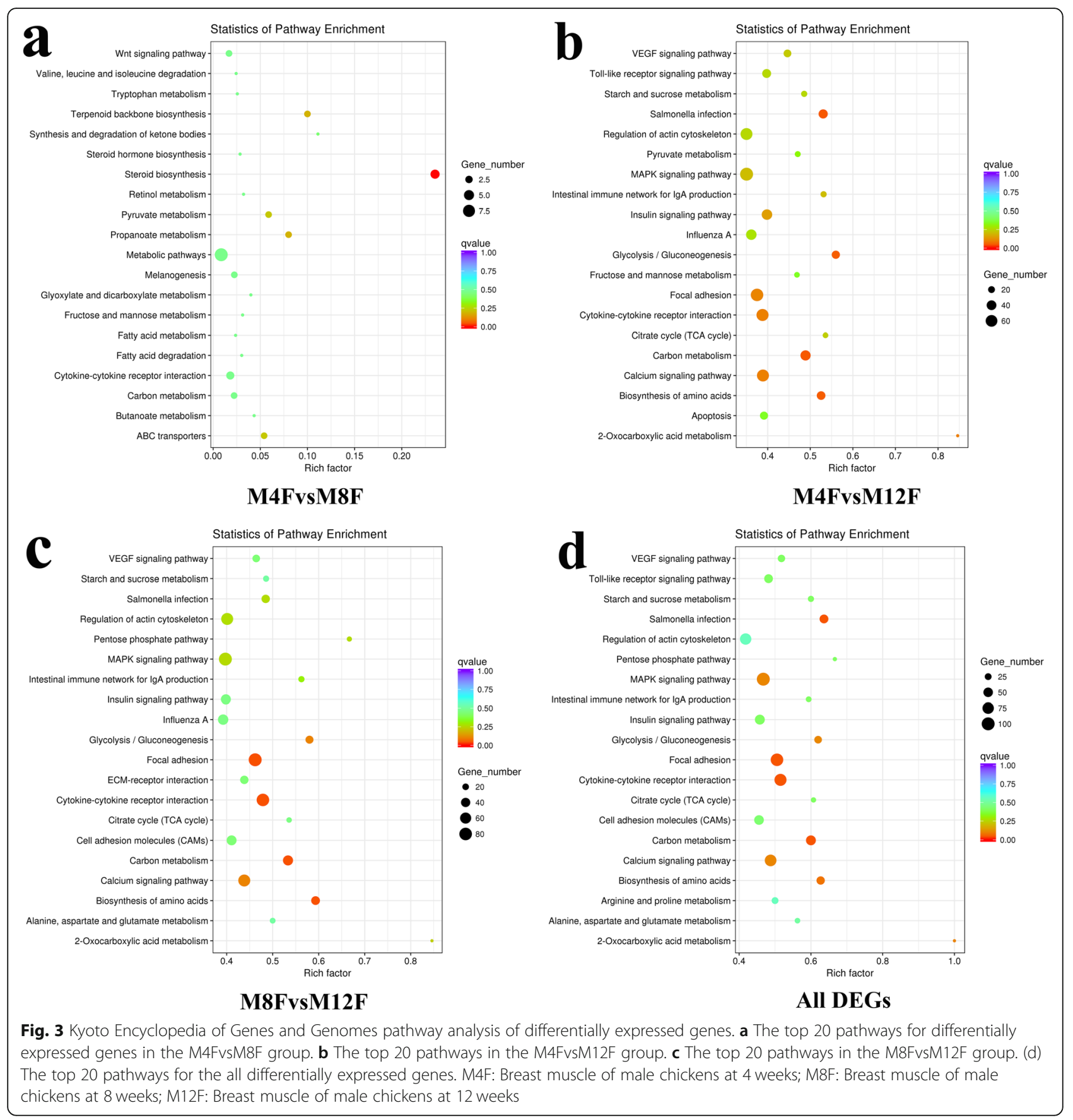

was used as the criterion and the significance analysis (P) was also carried out. The results showed that expression of the nine genes were significantly correlated between the RNA-seq and qPCR $(r \geq 0.95$ and $P \leq 0.05)$.

\section{Construction of PPI protein interaction network}

The result of RNA-seq showed that a total of 4608 DEGs were obtained in the three comparison groups. We extracted 2143 pairs of interaction relationships from the STRING database. Finally, the plug-in cytohubba of Cytoscape was used to screen the first 20 hub genes and visualize the network (Fig. 5).

Through further analysis, we found that 6 of the 20 hub genes were enriched in focal adhesion pathway, accounting for the highest proportion of the hub genes (Table S6). The focal adhesion pathway was one of the 6 significantly enriched pathways of 4608 DEGs and it is closely related to growth and development [16-18]. RAC2, one of the 6 
Table 3 Significant enrichment of KEGG pathways associated with growth and development

\begin{tabular}{|c|c|c|c|c|c|}
\hline Group & Name of the KEGG & Term ID & $\begin{array}{l}\text { DEGs } \\
\text { number }\end{array}$ & $\begin{array}{l}\text { Corrected } p \text { - } \\
\text { value }\end{array}$ & Genes name \\
\hline M4FvsM8F & Steroid biosynthesis & gga00100 & 4 & 0.000391 & NSDHL; SQLE; SC5D; HSD17B7 \\
\hline \multirow[t]{2}{*}{ M4FvsM12F } & Carbon metabolism & gga01200 & 44 & 0.049506 & PFKM; HK2; FBP1; FBP2; PKM; MDH2; DLAT \\
\hline & Salmonella infection & gga05132 & 35 & 0.049506 & MAPK11; FOS; FOSB; IL8L1; RHOG \\
\hline \multirow[t]{4}{*}{ M8FvsM12F } & $\begin{array}{l}\text { Cytokine-cytokine receptor } \\
\text { interaction }\end{array}$ & gga04060 & 79 & 0.041333 & $\begin{array}{l}\text { TGFB1; TGFB3; TGFBR2; BMPR2; GSF1R; VEGFA; EGF; } \\
\text { CCR5 }\end{array}$ \\
\hline & Focal adhesion & gga04510 & 85 & 0.041333 & $\begin{array}{l}\text { MYLK2; ACTN1; ACTN2; MAPK9; RAC2; VAV2; MYLK4; } \\
\text { HGF }\end{array}$ \\
\hline & Carbon metabolism & gga01200 & 48 & 0.043003 & PKM; FBP1; FBP2; HK1; CPS1; GOT2; GPI \\
\hline & Biosynthesis of amino acids & gga01230 & 35 & 0.043003 & PKM; PFKM; TKT; MAT1A; CTH \\
\hline \multirow[t]{4}{*}{ All DEGs } & Carbon metabolism & gga01200 & 54 & 0.04593 & PKM; HK1; HK2; HK3; DLAT \\
\hline & Focal adhesion & gga04510 & 93 & 0.04593 & FN1; PIK3CB; MYLK4; ACTN2; RAC2 \\
\hline & $\begin{array}{l}\text { Cytokine-cytokine receptor } \\
\text { interaction }\end{array}$ & gga04060 & 85 & 0.04593 & TGFB1; FAS; BMPR2; TGFB3; TGFBR2; \\
\hline & Salmonella infection & gga05132 & 42 & 0.04593 & MAPK9; MAPK11; FOSB; IL8L1 \\
\hline
\end{tabular}

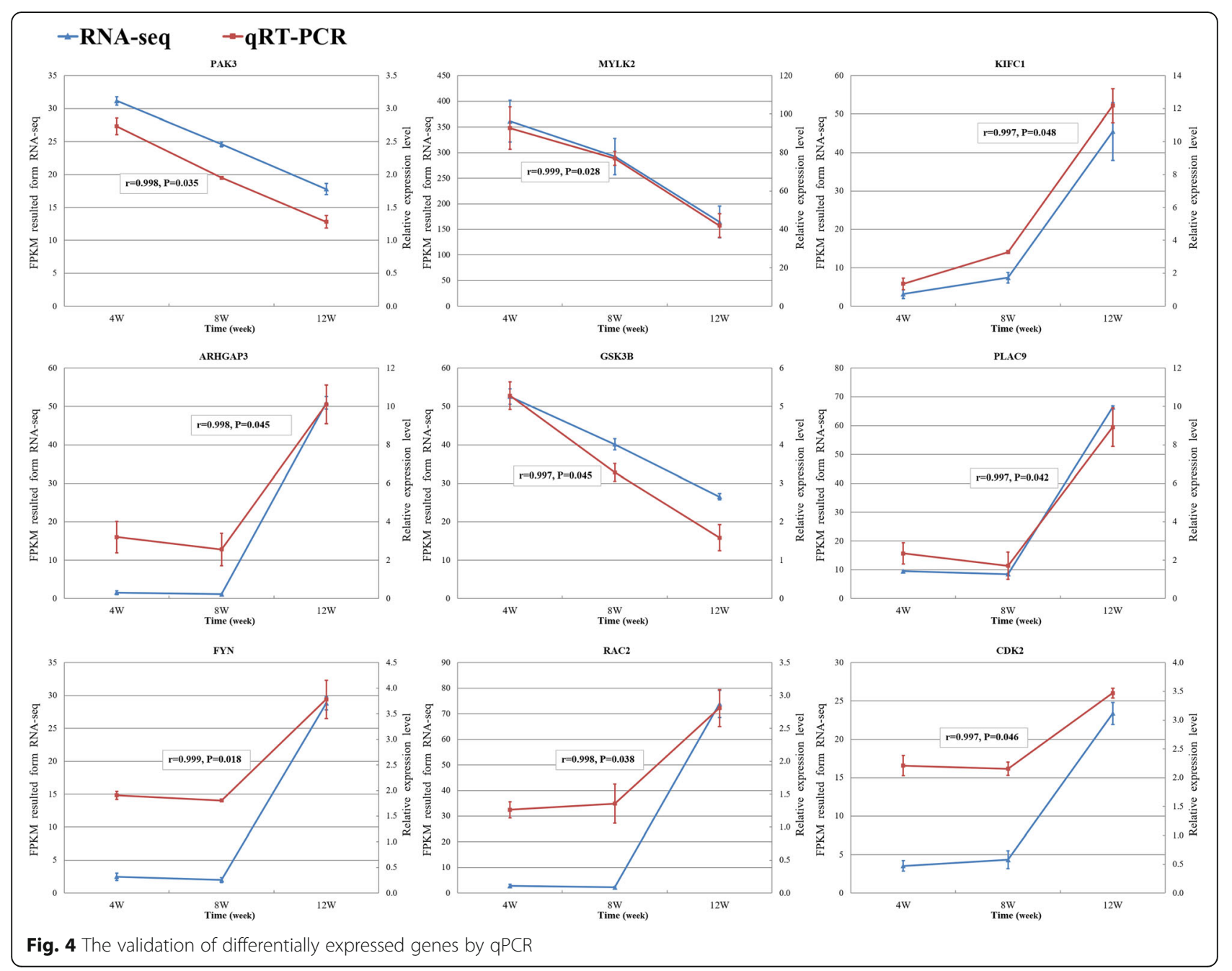




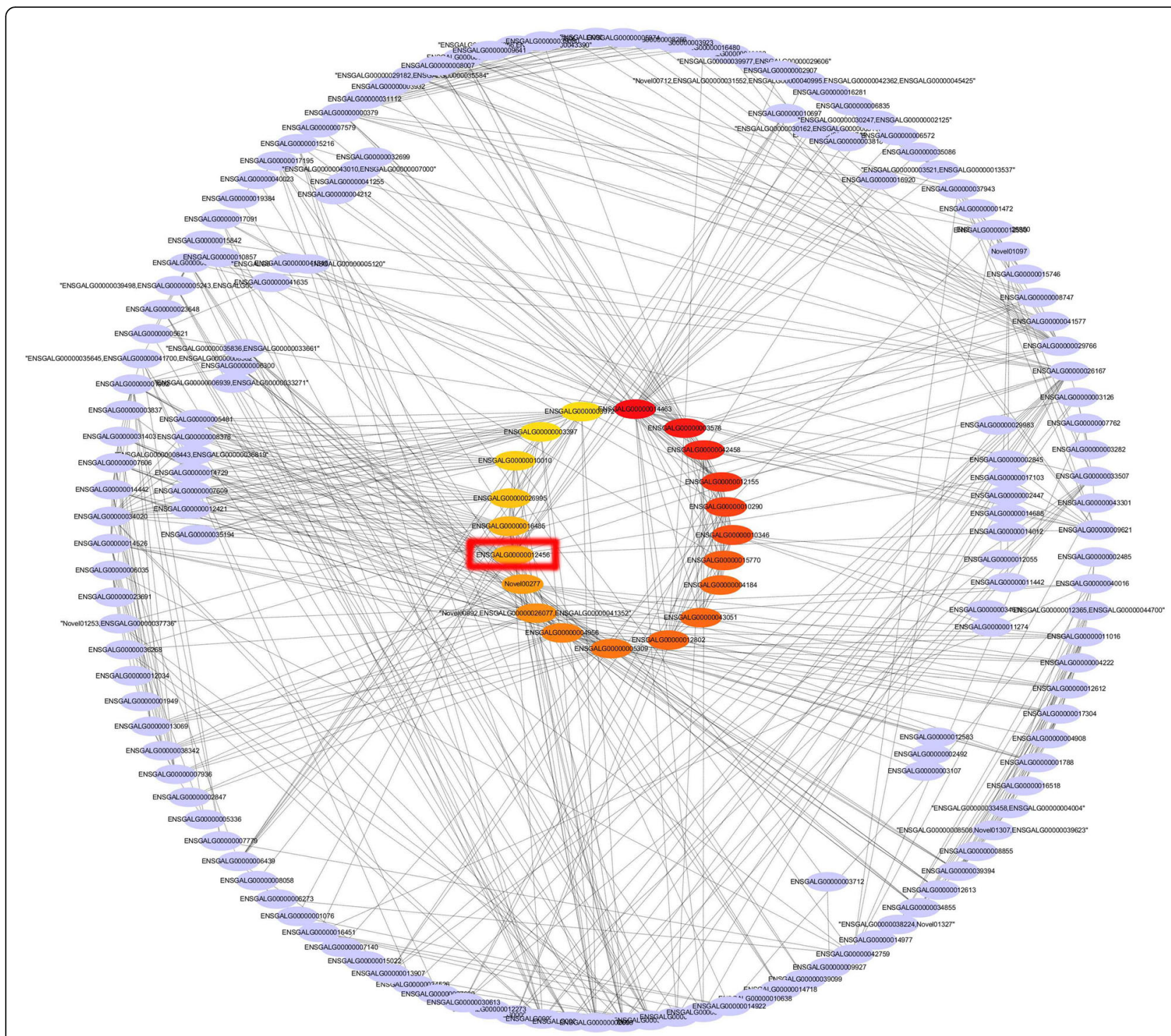

Fig. 5 Protein-protein interaction networks

genes enriched in focal adhesion, was at the core of the pathway (Fig. 6). Therefore, $R A C 2$ was selected as a key gene for cell level functional verification.

\section{RAC2 is involved in the PAKs/MAPK8 pathway}

The four interfering recombinant plasmids of $R A C 2$ (shRAC2-1, 2, 3 and 4) were transfected into DF-1 cells. The expression of $R A C 2$ was decreased in four groups (Fig. 7a) compared with the negative control group (NC), among which, the group of shRAC2-2 had the highest interference efficiency of about $60 \%$. The expression of $R A C 2$ was also decreased significantly $(P \leq 0.001)$ in $\operatorname{sh} R A C 2-2$ group. Therefore, $\operatorname{sh} R A C 2-2$ was chosen as an effective interference plasmid for functional verification.
The shRAC2-2 and NC plasmids were transfected into DF-1 cells cultured in 6-well plates, respectively. Total RNA was extracted $24 \mathrm{~h}$ after transfection and protein was extracted $48 \mathrm{~h}$ after transfection. Quantitative polymerase chain reaction (qPCR) showed that the expression of $R A C 2$ and its downstream genes $P A K 1$ and MAPK8 were significantly decreased $(P=0.00, P=0.003$ and $P=0.032$ ) in the shRAC2-2 group (Fig. $7 \mathrm{~b}$ ). However, the gene $P A K 3$ was significantly increased $(P=$ 0.011 ) in the shRAC2-2 group (Fig. 7b). Western Blot (WB) also showed that the protein expression of $R A C 2$, $P A K 1$ and MPAK8 were decreased in the shRAC2-2 group (Fig. 7c) and the full-length blots are presented in supplementary Figure S3. All the above results indicated that $R A C 2$ may affect the proliferation of DF-1 cells through $P A K 1 / P A K 3 / M A P K 8$ pathway. 


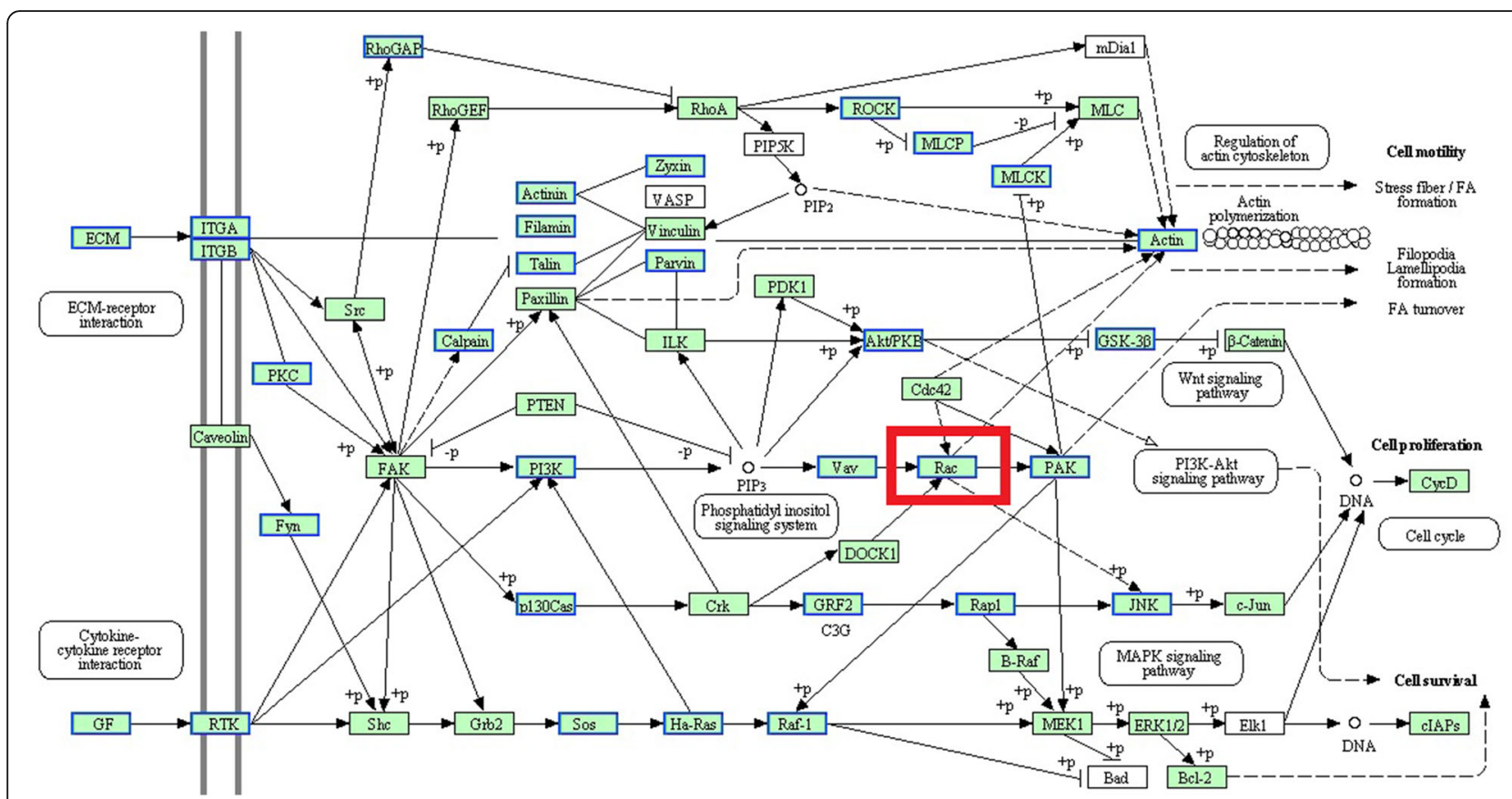

Fig. 6 The focal adhesion pathway and I have obtained the copyright permission to use the pathway

\section{$R A C 2$ promotes the proliferation of fibroblasts}

The shRAC2-2 and NC plasmids were transfected into DF-1 cells cultured in 96-well plates. The results of cell proliferation using CCK-8 showed that there was no significant difference in absorbance between the shRAC2-2 and NC groups at 0 and $12 \mathrm{~h}$. The absorbance of shRAC2-2 was decreased significantly at 24 and $36 \mathrm{~h}$ (Fig. 8a). The results of EdU also showed that the proportion of proliferative cells in shRAC2-2 group was significantly lower $(P=0.005)$ than that of the NC group (Fig. $8 \mathrm{~b}$ and c). It indicates that $R A C 2$ can affect the proliferation of DF-1 cells.

\section{Discussion}

Transcriptome sequencing can be used to study the regulation of broilers' growth and development systematically, and some achievements have also been made in recent years. Chen et al. [17] revealed $\mathrm{FoxO}_{\mathrm{O}} 3$ as a candidate gene for growth and development for chickens when studying the breast muscle of females of two breeds with divergent growth speed, using RNA-seq. Piorkowska et al. [19] collected the pectoral muscles of eight little hens, and divided them into two groups according to the different shear force. They found several genes related to muscle tenderness, including the $A S B 2$, THRSP and PLIN1. Li et al. [20] collected breast muscle of female Gushi chickens at $6,14,22$, and 30 weeks for RNA-seq, and found 388 known miRNAs and 31 novel miRNAs between developmental stages. Li et al. [21] also performed RNA-Seq analysis of breast muscle from female Gushi chickens at two physiological stages, including juvenile (G20W) and laying (G55W). The authors identified 186 lncRNAs and 881 mRNAs differentially expressed between the two stages, mainly involved in ECM-receptor interaction, glycerophospholipid metabolism, ubiquitin-mediated proteolysis, and the biosynthesis of amino acids.

In the current study, we collected the breast muscle of male Jinghai yellow chickens at 4, 8 and 12 weeks for RNA-seq and found some growth related genes of male chicken. Common differentially expressed genes SNCG and $A R H G D I B$ were mostly found to be related to cancer, and they can regulate cell proliferation, differentiation, invasion, metastasis and other cell behaviors [2225]. So we speculated that the two genes may regulate the growth and development of chicken by influencing cell behaviors.

Differentially expressed gene $M Y H 1 A$ is a member of myosin heavy chain $(\mathrm{MyHC})$ family. Myosin, consisting of two heavy chains $(M y H C)$ and four light chains $(M y L C)$ [26], is the largest component of muscle contractile tissue [27]. The $M y H C$ subtype mainly determines the types of muscle fiber [28]. In general, muscle fiber types can be categorized as slow-twitch oxidative (Type I), fast-twitch oxidative/glycolytic (Type IIa), and fast-twitch glycolytic fibers (Type IIb and IIx) [29]. At birth, muscle is composed of oxidative fibers and the proportion of oxidative fibers decreases while the proportion of glycolytic fibers increases during growth [30]. The type of muscle fiber is closely related to the meat 


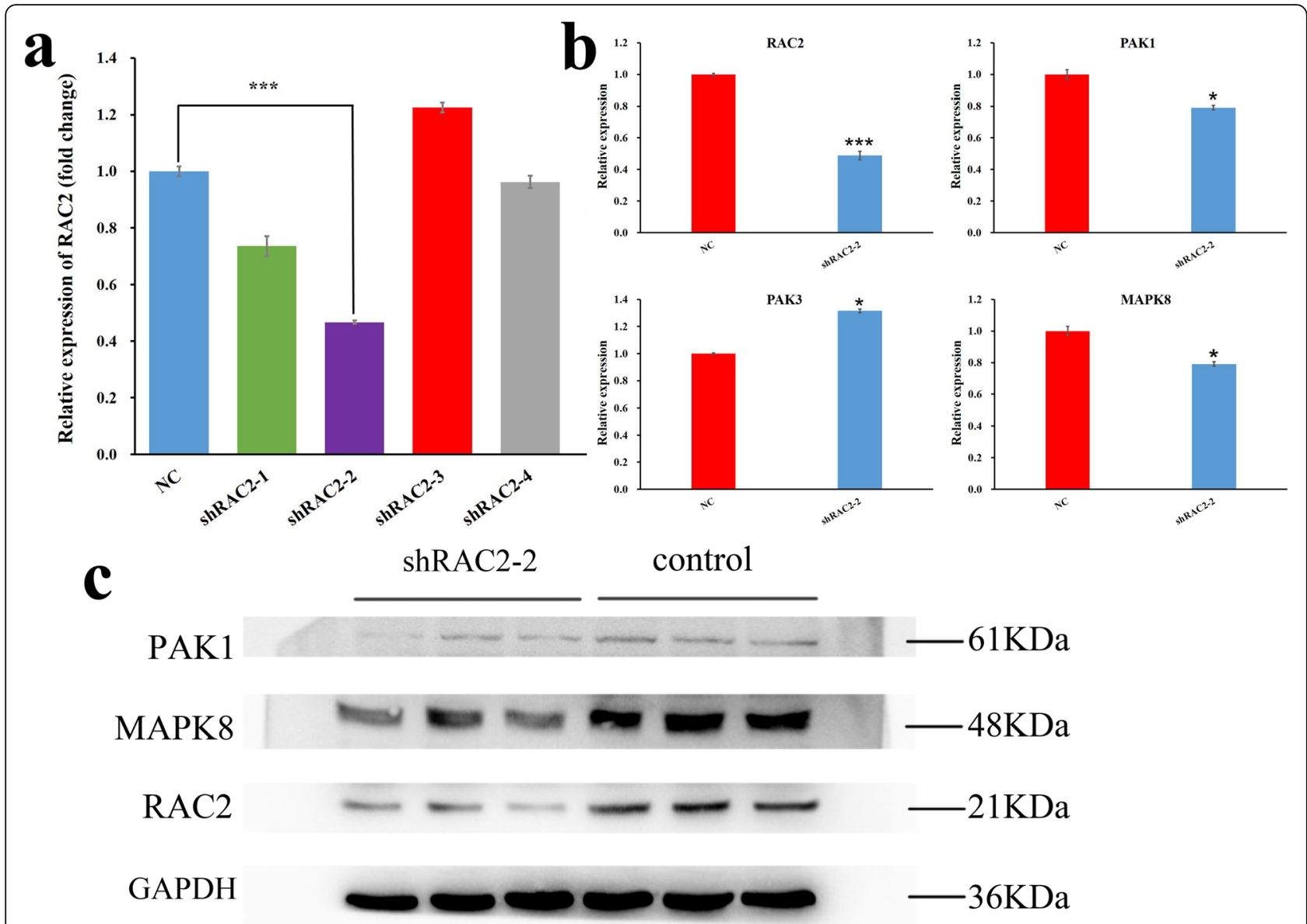

Fig. 7 The results of $\mathrm{qPCR}$ and western blot. a The expression of $R A C 2$ for the four interference plasmids. $\mathbf{b}$ Relative expression of mRNA for genes. c The protein expression of RAC2, PAK1 and MAPK8. The full-length blots are presented in supplementary Fig. S3. ${ }^{*} P \leq 0.05$, ${ }^{* * *} P \leq 0.001$

quality, because it fundamentally determines the $\mathrm{pH}$, tenderness, and intramuscular fat of muscle [31]. The growth process of poultry, especially the early growth stage, is an important stage in the transformation of muscle fiber types [32, 33]. In the study, RNA-seq showed that the expression of MYH1A was significantly decreased at 8 and 12 weeks compared with 4 weeks. In addition, other $M y H C$ subtypes such as $M Y H 1 B$, MYH1E, MYH1F, MYH1G and MYH9 were also differentially expressed among groups. The expression changes of $\mathrm{MyHC}$ subtypes may reflect the transformation of muscle fiber types and then affect the early growth and development of Jinghai yellow chicken.

Myosin light chain $(M y L C)$ can be further divided into essential myosin light chain $(E L C)$ and regulatory myosin light chain $(R L C)$, which are encoded by a variety of genes, including MYL1, MYL2, MYL3, etc. [34]. It is generally believed that the main function of $E L C$ is to maintain the configuration of heavy chain, while $R L C$ plays a role in regulating the activity of muscle fiber, and the proportion of different types for myosin light chains would affect the type and growth of muscle fiber [35]. In this experiment, we found that the expression of MYL1 had no significant change between 4 and 8 weeks, but significantly decreased at 12 weeks $(\mathrm{FDR} \leq 0.01)$. The expression of MYL6 also did not change significantly between 4 and 8 weeks, but increased significantly at 12 weeks (FDR $\leq 0.01$ ). Changes in the expression of these genes indicated that the proportion of muscle fiber types might be different at different growth stages.

Myocyte enhancer factor 2 (MEF2) belongs to the MADS-box transcription factor family and it has four members (MEF2A, MEF2B, MEF2C and MEF2D) [36, 37]. The activation of genes related to skeletal muscle growth and development were regulated by muscle specific transcription factors such as myogenic regulatory factors (MRFs), which have a homologous structure of bHLH (basic helix loop helix) [38]. The MADS-box region of MEF2 can interact with bHLH to activate the expression of skeletal muscle specific genes, and finally regulate the skeletal muscle growth and development [39]. In the study, the expression trends of the three DEGs (MEF2A, MEF2C and MEF2D) were consistent in different stages of growth, suggesting that they may play 


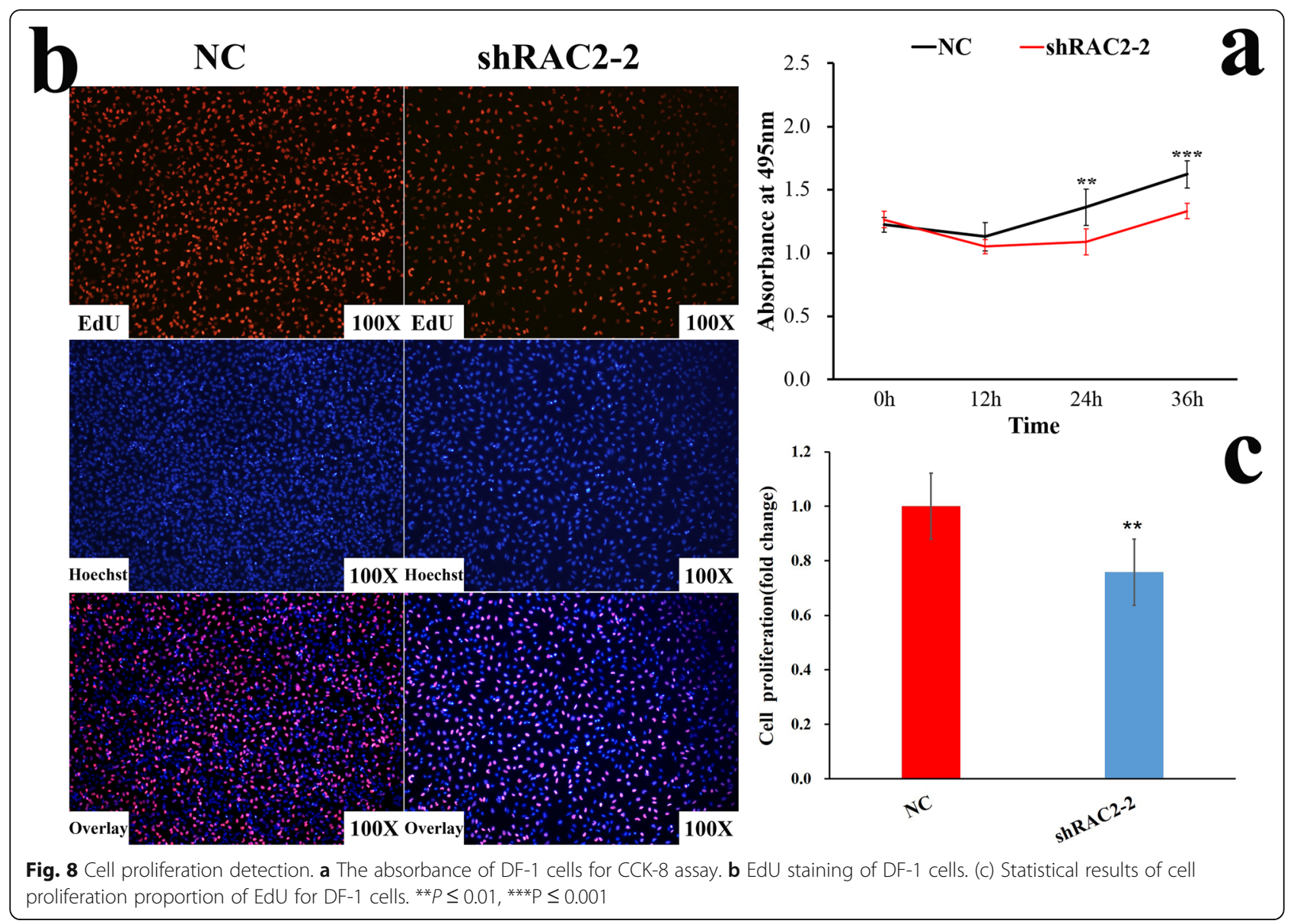

the same role in regulating the growth and development of chicken skeletal muscle.

Focal adhesion is a special structure in cells, and it is closely related to growth and development [16-18]. Using the plug-in cytohubba of Cytoscape, we found that 6 of 20 hub genes were enriched in the focal adhesion pathway, accounting for the highest proportion of hub genes. Among them, RAC2 was at the core of the pathway. Studies have shown that there were three subtypes of $R A C$ ( $R A C 1, R A C 2$ and $R A C 3$ ), and they have high homology [40]. Some experiments have also shown that the level of active $R A C 1$ was increased in $R A C 2$-deficient cells $[41,42]$. We speculated that $R A C 2$ and $R A C 1$ have some overlapping functions. P21-activated kinase (PAK) is an important effector of protein $R A C$ [43, 44]. PAKs are classified into two categories: PAK I and PAK II [45]. PAK I includes PAK1, PAK2 and PAK3 [46]. PAKS are involved in various biological effects, such as cytoskeleton recombination, cell migration, cell proliferation and gene transcription [47-49]. Members of the Mitogen-activated Protein Kinases (MAPKs) superfamily are important downstream signaling molecules of PAKs [50, 51]. $M A P K s$ are abundant in eukaryotic cells, which can transmit extracellular signals to the nucleus and regulate various physiological and biochemical processes in cells [52]. As a member of MAPK signaling pathway, MAPK8, also known as JNK, JNK1 and SAPK1, participates in many biological and molecular processes, such as cell proliferation, differentiation and apoptosis [53-55]. Wang et al. [56] found that MAPK8 could promote the differentiation of chicken embryonic stem cells into spermatogonial stem cells.

In the study, we also explored the function of $R A C 2$ on fibroblasts proliferation through the PAKs/MAPKs signaling pathway. Results of qPCR showed that the expression of $R A C 2$ was significantly lower than that of the NC group, and the expression of PAK1 was also significantly lower, which was consistent with the expression trend between RAC1 and PAK1 in other species [57-59]. The protein expression of $R A C 2$ and $P A K 1$ were also decreased in the shRAC2-2 group. However, the expression of $P A K 3$ was significantly increased, which was consistent with the results of Chen [60]. We infer that $R A C 2$ may act on PAKs in the same way as $R A C 1$, while the function of $P A K 3$ may be opposite to that of PAK1. The results of RNAi for $R A C 2$ showed that the expression of $M A P K 8$ was significantly lower than that of the NC group. Western Blot showed that MAPK8 protein 
was also decreased. Finally, CCK-8 and EdU assays both showed that proliferation of DF-1 cells was inhibited after transfection of $\operatorname{sh} R A C 2-2$. Therefore, it could be inferred that knockdown of $R A C 2$ inhibits the proliferation of DF- 1 cells by down-regulating $P A K 1$ and $M A P K 8$ while up-regulating $P A K 3$.

\section{Conclusions}

The study systematically revealed genes, BP terms and KEGG pathways related to growth and development of male Jinghai yellow chickens. It will lay a theoretical foundation for uncovering the molecular mechanism of skeletal muscle growth and development, and also has an important guiding role in practical production. Further functional research in DF-1 cells showed that differentially expressed gene $R A C 2$ might regulate cell proliferation by regulating $P A K s / M A P K 8$ pathway and affect the growth of chickens.

\section{Materials \\ Animals}

The chickens in the experiment were obtained from the same group of Jinghai yellow chicken in Jiangsu Jinghai Poultry Industry Group Co., Ltd. (Nantong, Jiangsu Province, China). At 4 (M4F), 8 (M8F) and 12 (M12F) weeks of age, three healthy male chickens with similar body weight (Table S1) were selected for slaughter, respectively. The chickens were first anesthetized with 8 $\mathrm{mg} / \mathrm{kg}$ of Xylazine Hydrochloride (SIGMA, X-1251). Then, when the feathers on both wings and tails fell down and failed to stimuli respond, it showed complete anesthesia. Following that, they were all sacrificed with bleeding of the carotid artery. Finally, the left breast muscles were collected and frozen in liquid nitrogen for RNA-seq.

\section{CDNA library construction and sequencing}

Total RNA was isolated using the TRIzol total RNA extraction kit (Invitrogen, Carlsbad, CA, USA). RNA degradation and contamination were monitored on $1 \%$ agarose gels. RNA purity was checked using the NanoPhotometer ${ }^{\circ}$ spectrophotometer (IMPLEN, CA, USA). RNA concentration was measured using Qubit $^{\circ}$ RNA Assay Kit in Qubit $^{\circ}$ 2.0 Flurometer (Life Technologies, CA, USA). RNA integrity was assessed using the RNA Nano 6000 Assay Kit on the Bioanalyzer 2100 system (Agilent Technologies, CA, USA). Sequencing libraries were generated using NEBNext $^{\circ}$ Ultra $^{\text {Tn }}$ RNA Library Prep Kit for Illumina ${ }^{\circ}$ NEB, USA). The cDNA libraries were finally sequenced on the Illumina NovaSeq 5000 platform and $150 \mathrm{bp}$ paired-end reads were generated.

\section{Data analysis}

Raw data (raw reads) of fastq format were firstly processed through in-house perl scripts and clean data (clean reads) were obtained in this step. At the same time, Q30 and GC content of the clean data were calculated. All the downstream analysis was based on the clean data.

We used HISAT (2.0.4) [61] for the reads mapping and HTSeq (v0.6.1) [62] to count the reads numbers mapped to genome. And then Fragments Per Kilobase per Million (FPKM) of each gene was calculated based on the length of the gene and reads count mapped to this gene. Differential expression analysis of the three age groups was performed using the DESeq $\mathrm{R}$ package (1.12.0) [63]. The DEGs were finally obtained between groups with the standard Fold Change (FC) $\geq 2$ and False Discovery Rate $(\mathrm{FDR}) \leq 0.05$.

Gene Ontology (GO) enrichment analysis of DEGs was implemented using the GOseq R package (2.12) [64] and the GO terms with corrected $p$-value $\leq 0.05$ were considered significantly enriched [65]. KOBAS (v2.0) [66] was used to analyze the KEGG pathway (corrected p-value $\leq 0.05)$ of DEGs.

PPI (protein-protein interactions) analysis of all DEGs was based on the STRING database [67]. We constructed the network by extracting the target gene list from the database. Blastx was used to align the target gene sequences to the selected reference protein sequences, and then the networks were built according to the known interaction of selected reference species. Finally, Cytoscape (3.6.1) was used to visualize the networks, and the plug-in cytohubba was used to find hub genes with the matthews correlation coefficient (MCC) method.

\section{Validation of the RNA-seq data}

Nine DEGs were selected to validate the RNA-seq data and they all have a high level of expression with FPKM $>10$. The primers (Table S2) were designed using Primer 5.0 based on the Gallus_gallus-5.0 (NCBI) and synthesized by Sangon Biotech Co., Ltd. (Shanghai, China). B2M [68] was selected as the internal reference in the quantitative polymerase chain reaction (qPCR). The qPCR was implemented using the ChamQ SYBR qPCR Master Mix Kit (Vazyme, Nanjing, China). Three technical replicates were performed for each sample. We calculated the relative expression of genes by $2^{-\triangle \Delta C t}$ method and used the SPSS13.0 software to analyze the correlation between qPCR and RNA-seq..

\section{$R A C 2$ recombination interference vector screening and function verification}

Four shRNAs (short hairpin RNAs) of RAC2 (Table 4) were designed according to the mRNA sequence (NCBI: NM_001201452.1) on website http://rnaidesigner. 
Table 4 The oligomeric single stranded DNA sequence of shRNAs

\begin{tabular}{|c|c|}
\hline Name & The oligomeric single-stranded DNA sequences \\
\hline ShRAC2-1 & $\overline{\text { GGATCCGCTATACCACTAATGCCTTCCTTCAAGAGAGGAAGGCATTAGTGGTATAGCTTाTाT }}$ \\
\hline $\operatorname{sh} R A C 2-2$ & GGATCCGGATCTTCGTGATGACAAAGATTCAAGAGATCTITGTCATCACGAAGATCCTTTाTा \\
\hline $\operatorname{sh} R A C 2-3$ & GGATCCGCTITCTCCTATTACATATCCTTCAAGAGAGGATATGTAATAGGAGAAAGCTIITाT \\
\hline $\operatorname{sh} R A C 2-4$ & GGATCCGCAGTGAGTGAGACCCAATAATTCAAGAGATTATTGGGTCTCACTCACTGCTITाT \\
\hline
\end{tabular}

Note: The underlines are the interference sequences and their complementary sequences

thermofisher.com/rnaiexpress/ and they were constructed into the plasmid vector by Gene Create company (Wuhan, China). The four recombinant plasmids were transfected into DF-1 cells, respectively. Expression level of $R A C 2$ was calculated $24 \mathrm{~h}$ after transfection, and the significance test for $R A C 2$ between interference group ( $\operatorname{sh} R A C 2-1,2,3$ and 4) and negative control group was carried out using SPSS13.0 software.

DF-1 cells were collected to detect the mRNA expression of downstream genes $24 \mathrm{~h}$ after transfection with shRNAs and detect the protein expression $48 \mathrm{~h}$ after transfection. Primers (Table S2) of RAC2 and its downstream genes for qPCR were also designed using primer 5.0 and synthesized by Sangon Biotech (Shanghai, China) as well.

RIPA (Radio Immunoprecipitation Assay, P0013B) and PMSF (Phenylmethanesulfonyl fluoride, ST506) for the protein extraction were purchased from Beyotime (Shanghai, China). The concentration of the extracted protein was detected using a Bradford Kit (Beyotime, Shanghai, P0006C). The primary antibodies of $R A C 2$ and PAK1 were purchased from ABclonal (Wuhan, China) and the dilution ratios were both 1:1000. For MAPK8, the primary and second antibodies were purchased from Sangon Biotech (Shanghai, China), and the dilution ratios were 1:1000 and 1:5000, respectively. For GAPDH, the primary antibody was purchased from HuaBio (Hangzhou, China), and we used a 1:2000 dilution ratio. And all the membranes were cut before staining according to the protein ladder (Thermo Fisher Scientific, MA, USA).

The CCK-8 Cell Counting kit (Vazyme, Nanjing, China) and EdU kit (RIBOBIO, Guangzhou, China) were used to detect cell proliferation in 96-well plates, according to the instructions. The proliferation of CCK- 8 was detected $0,12,24$ and $36 \mathrm{~h}$ after transfection. The proliferation of EdU was detected $24 \mathrm{~h}$ after transfection. Six biological replicates were set up in the CCK-8 assay. Four replicates were set up in the EdU assay and four visual fields in each replicate were randomly selected for statistical analysis.

\section{Statistical analysis}

The significance of CCK-8, EdU and mRNA expression between shRAC2-2 and $\mathrm{NC}$ groups was calculated using
SPSS13.0 software with the method IndependentSamples $T$ Test. All data were presented as mean \pm SD (standard deviation).

\section{Abbreviations}

DEGs: Differentially expressed genes; FC: Fold Change; FDR: False Discovery Rate; WB: Western Blot; PAKs: p21-activated kinases; MAPKs: Mitogen-activated Protein Kinases; GO: Gene Ontology; KEGG: Kyoto Encyclopedia of Genes and Genomes; PPI: Protein-protein interactions; MCC: Matthews correlation coefficient; qPCR: Quantitative polymerase chain reaction; CCK-8: Cell Counting Kit-8; EdU: 5-Ethynyl-2'- deoxyuridine; NC: Negative control group; FPKM: Fragments Per Kilobase per Million; MF: Molecular function; BP: Biological process; CC: Cell composition

\section{Supplementary Information}

The online version contains supplementary material available at https://doi. org/10.1186/s12864-021-07453-0.

Additional file 1: Figure S1. The agarose gel electrophoresis of total RNA.

Additional file 2: Figure S2. The distribution of reads in different regions of reference genome.

Additional file 3: Figure S3. Original images for western blot.

Additional file 4: Table S1. Body weight at different weeks.

Additional file 5: Table S2. Primer sequences for $\mathrm{QPCR}$.

Additional file 6: Table S3. Quality detection results for RNA.

Additional file 7: Table S4. The results of quality control for RNA-seq.

Additional file 8: Table S5. The results of comparison with reference genome for clean reads.

Additional file 9: Table S6. Information of the top 20 hub genes.

\section{Acknowledgements}

The authors thank Novogene for the technical support.

Authors' contributions

GXZ and PFW designed the study and drafted the manuscript. KZZ, MLH and XCZ collected samples for RNA-seq. GXZ, PFW, KZZ, MLH, XCZ and CQ contributed to laboratory experiments. $T T L$ and $T Z$ performed the data analysis. GXZ, KZX, GJD and JYW revised the paper. All authors read and approved the final manuscript.

\section{Funding}

The study was jointly supported by the Natural Science Foundation of Jiangsu Province (BK20181453), Key Laboratory of Animal (Poultry) Genetics Breeding and Reproduction, Ministry of Agriculture (poultrylab2018-10), the Special Funds Project for Transforming Scientific and Technological Achievements in Jiangsu Province (BA2018099), the China Agriculture Research System (CARS-41), and the Priority Academic Priority Academic Program Development of Jiangsu Higher Education Institutions (PAPD). The funding bodies played no role in the design of the study and collection, analysis, and interpretation of data and in writing the manuscript. 


\section{Availability of data and materials}

The raw data can be found in the NCBI BioProject database under the accession number PRJNA661705 (https://www.ncbi.nlm.nih.gov/sra/PRJNA661 705).

PPI (protein-protein interactions) analysis of all DEGs was based on the STRI NG database (https://string-db.org/).

The shRNAs were designed on the website of Thermo Fisher Scientific (http://rnaidesigner.thermofisher.com/rnaiexpress/).

The accession number of RAC2 is NM_001201452.1 on the website of NCBI (https://www.ncbi.nlm.nih.gov/).

\section{Declarations}

\section{Ethics approval and consent to participate}

The animal experiments performed in the study were all evaluated and approved by the Animal Ethics Committee of Yangzhou University.

\section{Consent for publication}

Not applicable.

\section{Competing interests}

The authors declare that they have no competing interests.

\section{Author details}

${ }^{1}$ College of Animal Science and Technology, Yangzhou University, Yangzhou 225009, China. ${ }^{2}$ Joint International Research Laboratory of Agriculture \& Agri-Product Safety, Yangzhou University, Yangzhou 225009, China. ${ }^{3}$ Jiangsu Jinghai Poultry Group Co. Ltd., Nantong 226100, China.

Received: 17 July 2020 Accepted: 19 February 2021

\section{Published online: 06 March 2021}

\section{References}

1. Qi J, Liu DY, Zhou GH, Xu XL. Characteristic flavor of traditional soup made by stewing Chinese yellow-feather chickens. J Food Sci. 2017;82(9):2031-40.

2. Weng Z, Xu Y, Li W, Chen J, Zhong M, Zhong F, Du B, Zhang B, Huang X. Genomic variations and signatures of selection in Wuhua yellow chicken. PLoS One. 2020;15(10):e0241137.

3. Zhang XX, Wang HH, Li M, Wu N, Xu XL. Near-freezing temperature storage $(-2 C)$ for extension of shelf life of chilled yellow-feather broiler meat: a special breed in Asia. J Food Process Pres. 2016;40:340-7.

4. Zhang C, Lin D, Wang Y, Peng D, Li H, Fei J, Chen K, Yang N, Hu X, Zhao Y, et al. Widespread introgression in Chinese indigenous chicken breeds from commercial broiler. Evol Appl. 2019;12(3):610-21.

5. Wang XQ, Chen X, Tan HZ, Zhang DX, Zhang HJ, Wei S, Yan HC. Nutrient density and slaughter age have differential effects on carcase performance, muscle and meat quality in fast and slow growing broiler genotypes. $\mathrm{Br}$ Poult Sci. 2013;54(1):50-61.

6. Zhao QB, Liao RR, Sun H, Zhang Z, Wang QS, Yang CS, Zhang XZ, Pan YC. Identifying Genetic Differences Between Dongxiang Blue-Shelled and White Leghorn Chickens Using Sequencing Data. G3 (Bethesda). 2018:8(2):469-76.

7. Xu J, Wang C, Jin E, Gu Y, Li S, Li Q. Identification of differentially expressed genes in longissimus dorsi muscle between Wei and Yorkshire pigs using RNA sequencing. Genes Genom. 2018;40(4):1-9.

8. Zhang Q, Zhu F, Liu L, Zheng CW, Wang DH, Hou ZC, Ning ZH. Integrating transcriptome and genome re-sequencing data to identify key genes and mutations affecting chicken eggshell qualities. PLoS One. 2015;10(5): e0125890.

9. Ren T, Li Z, Zhou Y, Liu X, Kang X. Sequencing and characterization of IncRNAs in the breast muscle of Gushi and arbor acres chicken. Genome. 2018;61(5):337-47.

10. Mott HR, Owen D. Allostery and dynamics in small G proteins. Biochem Soc Trans. 2018;46(5):1333-43.

11. Yan C, Theodorescu D. RAL GTPases: biology and potential as therapeutic targets in cancer. Pharmacol Rev. 2018;70(1):1-11.

12. Hodge RG, Ridley AJ. Regulating rho GTPases and their regulators. Nat Rev Mol Cell. 2016;17(8):496-510.

13. Bartok B, Hammaker D, Firestein GS. Phosphoinositide 3-kinase $\delta$ regulates migration and invasion of synoviocytes in rheumatoid arthritis. J Immunol. 2014;192(5):2063-70.
14. Cao H, Shibayama-Imazu T, Masuda Y, Shinki T, Nakajo S, Nakaya K. Involvement of Tiam1 in apoptosis induced by bufalin in HeLa cells. Anticancer Res. 2007;27(1a):245-9.

15. Wang Y, Lu YF, Li CL, Sun W, Li Z, Wang RR, He T, Yang F, Yang Y, Wang XL, et al. Involvement of Rac1 signalling pathway in the development and maintenance of acute inflammatory pain induced by bee venom injection. Br J Pharmacol. 2016;173(5):937-50.

16. Burridge K. Focal adhesions: a personal perspective on a half century of progress. FEBS J. 2017;284(20):3355-61.

17. Chen B, Xu J, He X, Xu H, Li G, Du H, Nie Q, Zhang X. A genome-wide mRNA screen and functional analysis reveal FOXO3 as a candidate gene for chicken growth. PLoS One. 2015;10(9):e0137087.

18. Xue Q, Zhang G, Li T, Ling J, Zhang X, Wang J. Transcriptomic profile of leg muscle during early growth in chicken. PLoS One. 2017;12(3):e0173824.

19. Piorkowska K, Zukowski K, Nowak J, Poltowicz K, Ropka-Molik K, Gurgul A. Genome-wide RNA-Seq analysis of breast muscles of two broiler chicken groups differing in shear force. Anim Genet. 2016;47(1):68-80.

20. Li Y, Chen Y, Jin W, Fu S, Li D, Zhang Y, Sun G, Jiang R, Han R, Li Z, et al. Analyses of MicroRNA and mRNA expression profiles reveal the crucial interaction networks and pathways for regulation of chicken breast muscle development. Front Genet. 2019;10:197.

21. Li D, Li F, Jiang K, Zhang M, Han R, Jiang R, Li Z, Tian Y, Yan F, Kang X, et al. Integrative analysis of long noncoding RNA and mRNA reveals candidate IncRNAs responsible for meat quality at different physiological stages in Gushi chicken. PLoS One. 2019;14(4):e0215006.

22. Fan C, Liu J, Tian J, Zhang Y, Yan M, Zhu C. siRNA targeting of the SNCG gene inhibits the growth of gastric carcinoma SGC7901 cells in vitro and in vivo by downregulating the phosphorylation of AKT/ERK. Exp Ther Med. 2018;154(4):209-16.

23. Shao $T$, Song $P$, Hua $H$, Zhang $H$, Sun $X$, Kong $Q$, Wang J, Luo T, Jiang Y. Gamma synuclein is a novel Twist1 target that promotes TGF-beta-induced cancer cell migration and invasion. Cell Death Dis. 2018;9(6):625.

24. Zhang M, Ding G, Zhou L, Shen T, Xu X, Zhao T, Jia S, Cao L. Interferon gamma inhibits CXCL8-induced proliferation and migration of pancreatic cancer BXPC-3 cell line via a RhoGDI2/Rac1/NF-kappaB signaling pathway. J Interf Cytokine Res. 2018;38(9):413-22.

25. Liu Y, Wei X, Guan L, Xu S, Yuan Y, Lv D, He X, Zhan J, Kong Y, Guo J, et al. Unconventional myosin VIIA promotes melanoma progression. J Cell Sci. 2018;131(4):jcs209924.

26. He Y, Gu M. Research progress of myosin heavy chain genes in human genetic diseases. Hereditas. 2017;39(10):877-87.

27. Liu B. Relationships of muscle fibre growth to meat quality traits in different broilers. China Agricultural University; 2005.

28. Reiser PJ. Current understanding of conventional and novel co-expression patterns of mammalian sarcomeric myosin heavy chains and light chains. Arch Biochem Biophys. 2019;662:129-33.

29. Qaisar R, Bhaskaran S, Van Remmen H. Muscle fiber type diversification during exercise and regeneration. Free Radic Biol Med. 2016;98:56-67.

30. Ismail I, Joo ST. Poultry meat quality in relation to muscle growth and muscle Fiber characteristics. Korean J Food Sci Anim Resour. 2017;37(6):87383.

31. Karlsson AH, Klont RE, Fernandez X. Skeletal muscle fibres as factors for pork quality. Livestock Production Science Exp Ther Med. 1999;60(2-3):255-69.

32. Zhao JP. The formation of muscle fiber characteristics and meat quality traits and their modulation by dietary nutrient density in broiler chickens. Chinese academy of agricultural sciences; 2010.

33. Li J. Study on the influence factors about growth and muscle fiber related gene expression of chickens. Sichuan Agricultural University; 2013.

34. Gregorich ZR, Cai W, Lin Z, Chen AJ, Peng Y, Kohmoto T, Ge Y. Distinct sequences and post-translational modifications in cardiac atrial and ventricular myosin light chains revealed by top-down mass spectrometry. J Mol Cell Cardiol. 2017;107:13-21.

35. Zhang $\mathrm{SZ}$, Yong $\mathrm{XU}$, Xie HQ, Xiu-Qun $\mathrm{LI}$, Wei YQ, Yang ZM. The possible role of myosin light chain in myoblast proliferation. Biol Res. 2009:42(1):121-32.

36. Black BL, Olson EN. Transcriptional control of muscle development by myocyte enhancer factor-2 (MEF2) proteins. Annu Rev Cell Dev Biol. 1998; 14(1):167-96.

37. Guo Y, Kühl SJ, Pfister AS, Cizelsky W, Denk S, Beermolz L, Kühl M. Comparative analysis reveals distinct and overlapping functions of Mef2C and Mef2d during cardiogenesis in Xenopus laevis. PLoS One. 2014;9(1): e87294. 
38. Edmondson DG, Lyons GE, Martin JF, Olson EN. Mef2 gene expression marks the cardiac and skeletal muscle lineages during mouse embryogenesis. Development. 1994;120(5):1251-63.

39. Taylor MV, Hughes SM. Mef2 and the skeletal muscle differentiation program. Semin Cell Dev Biol. 2017;72:33-44.

40. Gavillet M, Martinod K, Renella R, Wagner DD, Williams DA. A key role for Rac and Pak signaling in neutrophil extracellular traps (NETs) formation defines a new potential therapeutic target. Am J Hematol. 2018;93(2):269-76.

41. Li S, Yamauchi A, Marchal CC, Molitoris JK, Quilliam LA, Dinauer MC. Chemoattractant-stimulated Rac activation in wild-type and Rac2-deficient murine neutrophils: preferential activation of Rac2 and Rac2 gene dosage effect on neutrophil functions. J Immunol. 2002;169(9):5043-51.

42. Walmsley MJ, Ooi SK, Reynolds LF, Smith SH, Ruf S, Mathiot A, Vanes L, Williams DA, Cancro MP, Tybulewicz VL. Critical roles for Rac1 and Rac2 GTPases in B cell development and signaling. Science. 2003;302(5644): 459-62.

43. Ha BH, Boggon TJ. CDC42 binds PAK4 via an extended GTPase-effector interface. Proc Natl Acad Sci U S A. 2018;115(3):201717437.

44. Huang $H$, Jiang $H$, Zhang $X$, Wei L, Wang P, Liu F, Jian W, Bai M, Cheng M. Computer-aided drug design, synthesis and identification of disulfide compounds as novel and potential allosteric PAK1 inhibitors. RSC Adv. 2018; 8(22):11894-901.

45. Wu HY, Yang MC, Chu PC, Kulp SK, Chen CS, Wu HY, Yang MC, Chu PC, Kulp SK, Chen CS. Abstract 1360: novel function of p21-activated kinase 3 (PAK3) in regulating Akt phosphorylation and pancreatic cancer stem cell phenotypes. Cancer Res. 2017;77(13 Supplement):1360.

46. Lei M, Lu W, Meng W, Parrini MC, Eck MJ, Mayer BJ, Harrison SC. Structure of PAK1 in an autoinhibited conformation reveals a multistage activation switch. Cell. 2012;102(3):387-97.

47. Lezoualc'H F, Métrich M, Hmitou I, Duquesnes N, Morel E. Small GTPbinding proteins and their regulators in cardiac hypertrophy. J Mol Cell Cardiol. 2008;44(4):623-32.

48. Joachim R, Crawford JJ, Hoeflich KP, Weiru W. Inhibitors of p21-activated kinases (PAKs). J Med Chem. 2015;58(1):111.

49. Arias-Romero LE, Chernoff J. A tale of two Paks. Biol Cell. 2008;100(2):97108.

50. Inoue K, Patterson EK, Capretta A, Lawendy AR, Fraser DD, Cepinskas G. Carbon monoxide\&ndash;releasing molecule-401 suppresses polymorphonuclear leukocyte migratory potential by modulating F-actin dynamics. Am J Pathol. 2017;187(5):1121-33.

51. Liu X, Si W, Liu X, He L, Ren J, Yang Z, Yang J, Li W, Liu S, Pei F. JMJD6 promotes melanoma carcinogenesis through regulation of the alternative splicing of PAK1, a key MAPK signaling component. Mol Cancer. 2017;16(1): 175.

52. Guo Y, Guo C, Ha W, Ding Z. Carnosine improves diabetic retinopathy via the MAPK/ERK pathway. Exp Ther Med. 2019;17(4):2641-7.

53. Abdellah M, Ridgway LD, Korapati AL, Qingxiu Z, Ling T, Yibin W, Siddik ZH, Mills GB, Claret FOX. Sustained activation of JNK/p38 MAPK pathways in response to cisplatin leads to Fas ligand induction and cell death in ovarian carcinoma cells. J Biol Chem. 2003;278(21):19245-56.

54. Kim SW, Muise AM, Lyons PJ, Ro HS, Kim SW, Muise AM, Lyons PJ, Ro HS. Regulation of adipogenesis by a transcriptional repressor that modulates MAPK activation. J Biol Chem. 2001;276(13):10199-206.

55. Tournier C, Hess P, Yang DD, Xu J, Turner TK, Nimnual A, Bar-Sagi D, Jones SN, Flavell RA, Davis RJ. Requirement of JNK for stress-induced activation of the cytochrome c-mediated death pathway. Science. 2000;288(5467):870-4.

56. Wang Y, Bi Y, Zuo Q, Zhang W, Li D, He NN, Cheng S, Zhang YN, Li B. MAPK8 regulates chicken male germ cell differentiation through JNK signaling pathway. J Cell Biochem. 2017;119(2):1548-57.

57. Fortin DA, Davare MA, Srivastava T, Brady JD, Nygaard S, Derkach VA, Soderling TR. Long-term potentiation-dependent spine enlargement requires synaptic Ca2+-permeable AMPA receptors recruited by CaM-kinase I. J Neurosci. 2010;30(35):11565-75.

58. Okada T, Lee AY, Qin LX, Agaram N, Mimae T, Shen Y, O'Connor R, LopezLago MA, Craig A, Miller ML, et al. Integrin-alpha10 dependency identifies RAC and RICTOR as therapeutic targets in high-grade myxofibrosarcoma. Cancer Discov. 2016;6(10):1148-65.

59. Wei L, Min Z, Ronald N, Susanne U, Jiawei J, Taglieri DM, Sukhpal P, Junhong G, Hoyee T, Rui-Ping X. Pak1 as a novel therapeutic target for antihypertrophic treatment in the heart. Circulation. 2011;124(24):2702-15.
60. Cheng JZ. PAK3 as a novel target for antihypertrophic treatment in the heart. Nanjing University; 2016.

61. Kim D, Langmead B, Salzberg SL. HISAT: a fast spliced aligner with low memory requirements. Nat Methods. 2015;12(4):357-60.

62. Simon A, Paul Theodor P, Wolfgang H. HTSeq--a Python framework to work with high-throughput sequencing data. Bioinformatics. 2015;31(2):166-9.

63. Anders $\mathrm{S}$, Huber W. Differential expression analysis for sequence count data. Genome Biol. 2010;11(10):R106.

64. Young MD, Wakefield MJ, Smyth GK, Oshlack A. Gene ontology analysis for RNA-seq: accounting for selection bias. Genome Biol. 2010;11(2):R14.

65. Kanehisa M, Araki M, Goto S, Hattori M, Hirakawa M, Itoh M, Katayama T, Kawashima S, Okuda S, Tokimatsu T et al. KEGG for linking genomes to life and the environment. Nucleic Acids Res. 2008;36(1):D480-484

66. Xie C, Mao X, Huang J, Ding Y, Wu J, Dong S, Kong L, Gao G, Li CY, Wei L. KOBAS 2.0: a web server for annotation and identification of enriched pathways and diseases. Nucleic Acids Res. 2011;39(suppl_2):W316-22.

67. Andrea F, Damian S, Sune F, Michael K, Milan S, Alexander R, Jianyi L, Pablo M, Peer B, Christian VM. STRING v9.1: protein-protein interaction networks, with increased coverage and integration. Nucleic Acids Res. 2013;41:D808-15.

68. Bagés S, Estany J, Tor M, Pena RN. Investigating reference genes for quantitative real-time PCR analysis across four chicken tissues. Gene. 2015; 561(1):82-7.

\section{Publisher's Note}

Springer Nature remains neutral with regard to jurisdictional claims in published maps and institutional affiliations.

\section{Ready to submit your research? Choose BMC and benefit from:}

- fast, convenient online submission

- thorough peer review by experienced researchers in your field

- rapid publication on acceptance

- support for research data, including large and complex data types

- gold Open Access which fosters wider collaboration and increased citations

- maximum visibility for your research: over $100 \mathrm{M}$ website views per year

At BMC, research is always in progress.

Learn more biomedcentral.com/submissions 